\section{Cool-season Grasses for Overseeding Sport Turfs: Germination and Performance under Limiting Environmental Conditions}

\author{
Francesco Rossini, Roberto Ruggeri ${ }^{1}$, Tiziano Celli, \\ Francesco Maria Rogai, and Ljiljana Kuzmanović \\ Department of Agriculture and Forest Sciences, University of Tuscia, via San \\ Camillo de Lellis, 01100 Viterbo, Italy
}

\author{
Michael D. Richardson \\ Department of Horticulture, University of Arkansas, Fayetteville, AR 72701
}

Additional index words. turfgrass, perennial ryegrass, meadow fescue, annual ryegrass, spreading ryegrass, shade

\begin{abstract}
In the transition zone, warm-season grasses are often overseeded with diploid perennial ryegrass (Lolium perenne $\mathrm{L} ., 2 n=2 x=14$ ) to provide a temporary green surface for winter sporting activities. Because improved cultivars of perennial ryegrass will often persist into summer in overseeded turf, alternative cool-season grasses have been developed to facilitate more rapid transition back to the warm-season species. Limited information is available on these alternative species, especially with regard to their germination characteristics under shade and performance under limiting factors, such as low temperature and restricted photoperiod. Greenhouse and growth chamber studies were designed to test four alternative overseeding grasses in comparison with diploid perennial ryegrass, to verify their potential use in the artificial environment of modern stadiums. Meadow fescue (Festuca pratensis Huds.), tetraploid perennial ryegrass (Lolium perenne L., $2 n=4 x=28$ ), annual ryegrass (Lolium multiflorum Lam.), and spreading diploid perennial ryegrass [Lolium perenne L. subsp. stoloniferum (C. Lawson) Wipff.] were tested. Six different shade treatments were used in the greenhouse study, including $30 \%, 50 \%, 70 \%, 90 \%$, and $100 \%$ shade and a nonshaded control ( $0 \%$ shade). Germination was monitored daily over a 21 -day period by counting and removing emerged seedlings. The experimental design for this study was a randomized complete block design, with four replications of each species and shade level for a total of 120 experimental units. In the growth chamber study, the same plant material was tested simulating optimal, suboptimal, and critical environmental conditions that can be potentially found within a modern sport facility. In the greenhouse study, the highest final germination was observed with annual ryegrass at $90 \%$ shade $(98.7 \%)$, whereas the lowest for tetraploid perennial ryegrass at $30 \%$ shade $(58.8 \%)$. Annual ryegrass was the fastest emerging species, whereas meadow fescue the slowest. In the growth chamber study, in comparison with perennial ryegrass, the following results may be summarized: 1) meadow fescue and tetraploid ryegrass showed coarser leaf texture, similar growth rates and Normalized Difference Vegetation Index (NDVI) value; 2) annual ryegrass had similar leaf texture, accelerated growth characteristics, and lower NDVI value; and 3) spreading perennial ryegrass displayed finer leaf texture, lower vertical growth, and similar NDVI value.
\end{abstract}

For turf managers in the transition zone, overseeding warm-season grasses with a coolseason species is a common practice to maintain aesthetics and playability during the winter

Received for publication 28 Sept. 2018. Accepted for publication 17 Dec. 2018

The authors thank Christian Ritz, associate professor in statistics from the Department of Nutrition, Exercise and Sports of the University of Copenhagen, for his precious assistance with the statistics used in Expt. 1; and CONI Servizi SPA for providing weather data from the Stadio Olimpico of Rome. ${ }^{1}$ Corresponding author. E-mail: r.ruggeri@unitus.it. This is an open access article distributed under the CC BY-NC-ND license (https://creativecommons. org/licenses/by-nc-nd/4.0/). season (Mazur and Rice, 1999). Even when climatic conditions are ideal to overseed with a cool-season species, the existing turf can reduce seed germination. In addition to competition for nutrients and water, light also could be a limiting factor for adequate germination in an overseeded turf (Jellicorse et al., 2009). The response of seeds to light can control the timing of germination in the field, which is a key factor in survival and fitness of the resulting seedlings (Pons, 2000). These features are crucial in highly trafficked sports turf, where the interval between overseeding and sport competition is usually very short. Small-seeded species were found to be more dependent on light for germination than largeseeded ones (Milberg et al., 2000; Scarici et al., 2018). Although some authors reported that light and temperature availability greatly influenced germination of warm-season grasses (Jellicorse et al., 2009; Shin et al., 2006; Zuk et al., 2005), there have been limited studies on the effects of reduced light on cool-season species.

Light reduction has a number of deleterious morphological and physiological consequences that contribute to the reduction of ornamental value, wear tolerance, and recuperative potential of the turf (Cereti et al., 2004; Gardner and Taylor, 2002). In recent years, the problems of shade and associated microclimate effects have increased in sport fields. Modern stadium design, based on semi or fully enclosed sport buildings, creates a shaded environment that substantially increases stress on turfgrass. Moreover, during the winter time, low temperature, photoperiod reduction, and intensive sporting activity also can contribute to damage on sports surfaces. As such, exploring new turfgrass species and varieties adapted to the modified environment of modern stadiums represents a great potential to improve sports turf performance.

Diploid perennial ryegrass (Lolium perenne L., $2 n=2 x=14$ ) is the predominant species used to overseed sport fields, due to its rapid establishment, high wear tolerance, ability to tolerate close mowing, and medium to fine leaf texture (Cereti et al., 2010; Schmidt and Shoulders, 1980). However, ryegrass is often characterized as having poor shade tolerance (Cereti et al., 2004; Gardner and Taylor, 2002). Furthermore, newer cultivars have improved heat tolerance, which has led to their longer persistence into summer and worsened spring transition of the permanent turf (Horgan and Yelverton, 2001; Summerford et al., 2016). For these reasons, research investigating alternative overseeding species is warranted.

Meadow fescue (Festuca pratensis Huds.) and tetraploid perennial ryegrass (Lolium perenne L., $2 n=4 x=28$ ) have been studied for a possible use in turfgrass overseeding programs due to their good germination vigor, color, quality, and improved transition characteristics compared with perennial ryegrass (Richardson et al., 2007; Summerford et al., 2009). In addition, a recent study found that increased $\mathrm{N}$ rate and mowing height improved the traffic tolerance of these two species (Summerford et al., 2016). New turf-type annual ryegrasses (Lolium multiflorum Lam.) also have been developed in recent years. These annual ryegrasses facilitate easier spring transition compared with perennial ryegrass and possess finer texture and improved color compared with previous annual ryegrass cultivars (Hargey et al., 2016). Performance and quality of recent cultivars of annual ryegrass have been compared with diploid perennial ryegrass cultivars, and the results showed that transition of turf-type annual ryegrasses occurred $\approx 1$ month earlier that diploid perennial ryegrass (Fontanier and Steinke, 2017; Nelson et al., 2005). Even though 
perennial ryegrass is usually described as a loosely to densely tufted, bunch-type plant, stoloniferous or rhizomatous ryegrass has been observed in different countries since the mid-20th century (Harris et al., 1979; Hayes, 1971; Kydd, 1966; Mitchell, 1956). Recently, a new subspecies of perennial ryegrass has been bred: Lolium perenne L. subsp. stoloniferum (C. Lawson) Wipff. Its aggressive spreading growth habit has resulted in greater turf density and recuperative potential. The high regenerative potential gives it the ability to quickly repair itself from traffic damage and to suppress undesirable weeds (Masin and Macolino, 2016).

The objectives of this study were to determine the germination features and performance of alternative cool-season species under limiting environmental conditions compared with perennial ryegrass, for their potential use in sport turfs.

\section{Materials and Methods}

Expt. 1: Plant materials, growth condition, and experimental design

An experiment was conducted in the Rosen Alternative Control Center Greenhouses at the University of Arkansas, Fayetteville, AR (lat. $36.0678^{\circ} \mathrm{N}$, long. $94.1737^{\circ} \mathrm{W}, 427 \mathrm{~m}$ above sea level) during Jan. and Feb. 2015. Temperature in the greenhouse was maintained between 16 and $22{ }^{\circ} \mathrm{C}$ and no supplemental lighting was used. Because not all the entries (cultivar or selection) used for this experiment were fully characterized, before starting the germination tests, seed weights were determined by weighing eight replicates of 100 seeds each. The entries tested in this study and their mean thousand seed weight are reported (Table 1).

A total of 220 seeds of each entry were sown into $12-\mathrm{cm}$-diameter plastic pots that contained a silt-loam soil that was native for the region. The soil is characterized as a Captina silt loam (fine-silty, siliceous, active, mesic Typic Fragiudults with an average $\mathrm{pH}$ of 6.2). The soil was sterilized by autoclaving at $120{ }^{\circ} \mathrm{C}$ to ensure that no weed seed contamination occurred.

Six different shade treatments were used in this study, including $30 \%, 50 \%, 70 \%$, $90 \%$, and $100 \%$ shade and a nonshaded control ( $0 \%$ shade). Plastic rings were cut from polyvinyl chloride (PVC) pipe $(15 \mathrm{~cm}$ diameter) to a height of $3.0 \mathrm{~cm}$ so that the ring would fit directly over the pots. Shade cloths (Bulk Shadecloth; International Greenhouse Co., Danville, IL) corresponding to the desired shade levels were stretched over the PVC rings and cinched tightly to the outside of the ring with plastic fasteners. All pots were watered to saturation before planting and then they were lightly irrigated daily to ensure proper soil moisture conditions for germination. Germination was monitored daily over a 21-day period by counting and removing emerged seedlings. The experimental design for this study was a randomized complete block design with four replications of each entry and shade level for a total of 120 experimental units.

\section{Expt. 2: Growth conditions,} measurements, and experimental design

A growth chamber study was conducted at the University of Tuscia, Viterbo, Italy, to determine the effects of reduced photoperiod and temperature on the performance of coolseason turfgrasses. The same plant material from Expt. 1 was used in Expt. 2. Seeds of each species were sown into 14-cm-diameter plastic pots that contained a sandy-loam soil with a $\mathrm{pH}$ of 6.6. For each species, seeding rate was calculated to obtain a final plant density of two plants $/ \mathrm{cm}^{2}$. Within a week after sowing, emergence was uniform for all treatments and grass was mowed three times before reaching the final mowing height (2.5 $\mathrm{cm})$. Plants were watered as needed to maintain soil moisture near field capacity. Each pot was fertilized weekly with $100 \mathrm{~mL}$ of a nutrient solution made up by diluting $60 \mathrm{~mL}$ of a commercial liquid fertilizer $(8 \% \mathrm{~N}-4 \%$ $\mathrm{P}_{2} \mathrm{O}_{5}-6 \% \mathrm{~K}_{2} \mathrm{O}$ ) in $3 \mathrm{~L}$ distilled water. Collection of the data started when all the pots reached $100 \%$ green cover.

The species were tested under three different environmental conditions classified as Environment 1 (optimal), Environment 2 (suboptimal), and Environment 3 (limiting). Photoperiod and temperatures related to each environment are reported in Table 2. While in Environment 1 grasses were maintained under optimal growing conditions (Di Paola and Beard, 1992; Du et al., 2009), parameters for Environments 2 and 3 were designed to mimic winter conditions from a weather station located within the Stadio Olimpico of Rome (Fig. 1).

Each environmental treatment was imposed for $20 \mathrm{~d}$ on 20 pots (five species replicated four times) and was repeated two times. Because only one chamber was used, the experiment was run six times and environmental treatments were randomly allocated to runs (Hammer and Hopper, 1997). The pots were arranged in blocks to account for within chamber variation. New pots for each environment and each run were used and sowing was shifted to account for similarly aged plants. The growth chamber had the following dimensions: $200 \mathrm{~cm} \times 212 \mathrm{~cm} \times$ $200 \mathrm{~cm}$ (height). A combination of fluorescent and metal-halide lamps provided a photosynthetically active radiation $(P A R)$ of $250 \mu \mathrm{mol} \cdot \mathrm{m}^{-2} \cdot \mathrm{s}^{-1}$ at the pot level and the chamber was maintained at $80 \%$ relative humidity using a humidifier. A Sun

Table 1. Entries tested and corresponding thousand-seed weight.

\begin{tabular}{lllc}
\hline Entry & \multicolumn{1}{c}{ Type } & \multicolumn{1}{c}{ Species } & $\mathrm{Wt} / 1000$ seeds $(\mathrm{g})$ \\
\hline APR 2477 & Experimental selection & Diploid perennial ryegrass & 1.82 \\
APRT 2114 & Experimental selection & Tetraploid perennial ryegrass & 2.99 \\
AMF 116 & Experimental selection & Meadow fescue & 2.42 \\
SAVANT & Cultivar & Spreading diploid perennial ryegrass & 1.65 \\
BARTERRA & Cultivar & Annual ryegrass & 1.84 \\
\hline
\end{tabular}

Table 2. Growing conditions of the three treatments tested.

\begin{tabular}{|c|c|c|c|}
\hline & \multicolumn{3}{|c|}{ Treatments } \\
\hline & $\begin{array}{l}\text { Environment } 1 \\
\text { (optimal) }\end{array}$ & $\begin{array}{c}\text { Environment } 2 \\
\text { (suboptimal) }\end{array}$ & $\begin{array}{c}\text { Environment } 3 \\
\text { (limiting) }\end{array}$ \\
\hline Photoperiod (light/dark, h) & $14 / 10$ & $10 / 14$ & $8 / 16$ \\
\hline Daily light integral $\left(\mathrm{mol} \cdot \mathrm{m}^{-2}\right)$ & 12.6 & 9.0 & 7.2 \\
\hline Day temperature $\left({ }^{\circ} \mathrm{C}\right)$ & 20 & 15 & 10 \\
\hline Night temperature $\left({ }^{\circ} \mathrm{C}\right)$ & 16 & 10 & 7 \\
\hline
\end{tabular}

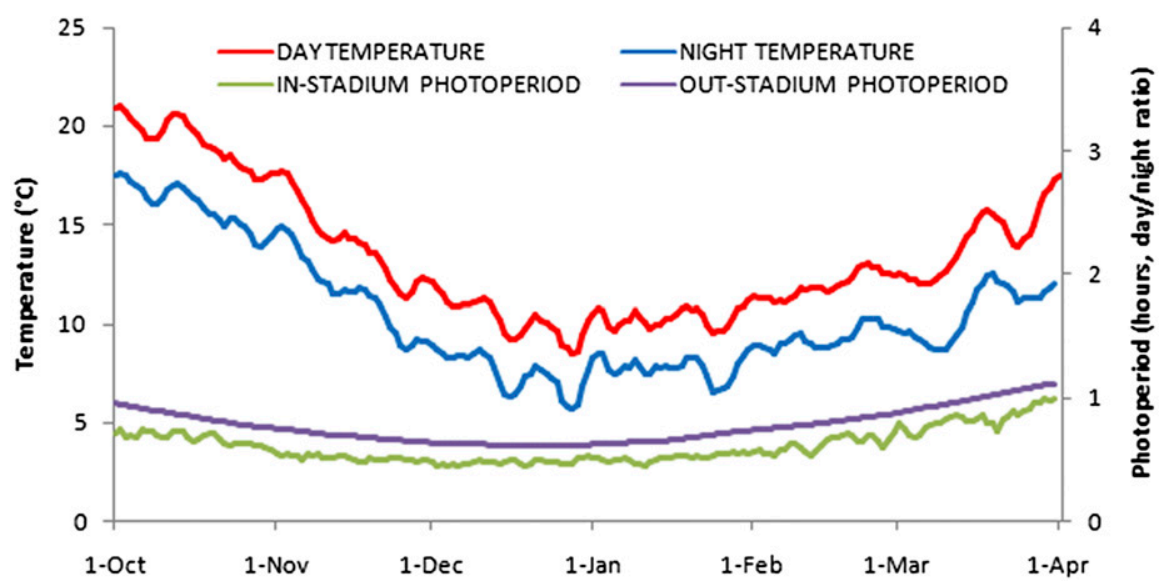

Fig. 1. Average day and night temperatures within the Stadio Olimpico of Rome and photoperiods in the stadium and out from the stadium (5-year average). 
Scan Probe-SS1 (Delta-T Devices Ltd, Cambridge, UK) was used twice a week to verify that $P A R$ was uniform throughout the experiment.

Grass response was measured twice each week as clipping yield [mg dry matter (DM)/ $\mathrm{cm}^{2} / \mathrm{d}$ ], vertical growth rate $\left(\mathrm{cm} \cdot \mathrm{d}^{-1}\right)$, leaf texture (mm width) and NDVI. For each pot,
NDVI was measured using a Dycam Agricultural Digital Camera (ADC; Dycam Inc., Chatworth, CA). The ADC was tailored for multiband photography in the red (635-667 $\mathrm{nm})$ and near infrared (835-870 $\mathrm{nm})$ wavebands, with spatial resolution of $496 \times 365$ pixels, the lens having a fixed focus of 4.5 . The field of view was equivalent to that of a lens with $60 \mathrm{~mm}$ focal length in 35-mm film format. Pictures were taken after each mowing in nadir view from a height of $\approx 130 \mathrm{~cm}$, and images were processed using the software (Band Rationing Image Viewer, BRIV-32) provided with the camera (Ruggeri et al., 2016). Leaf texture measurements were taken before mowing from the midpoint of the third fully
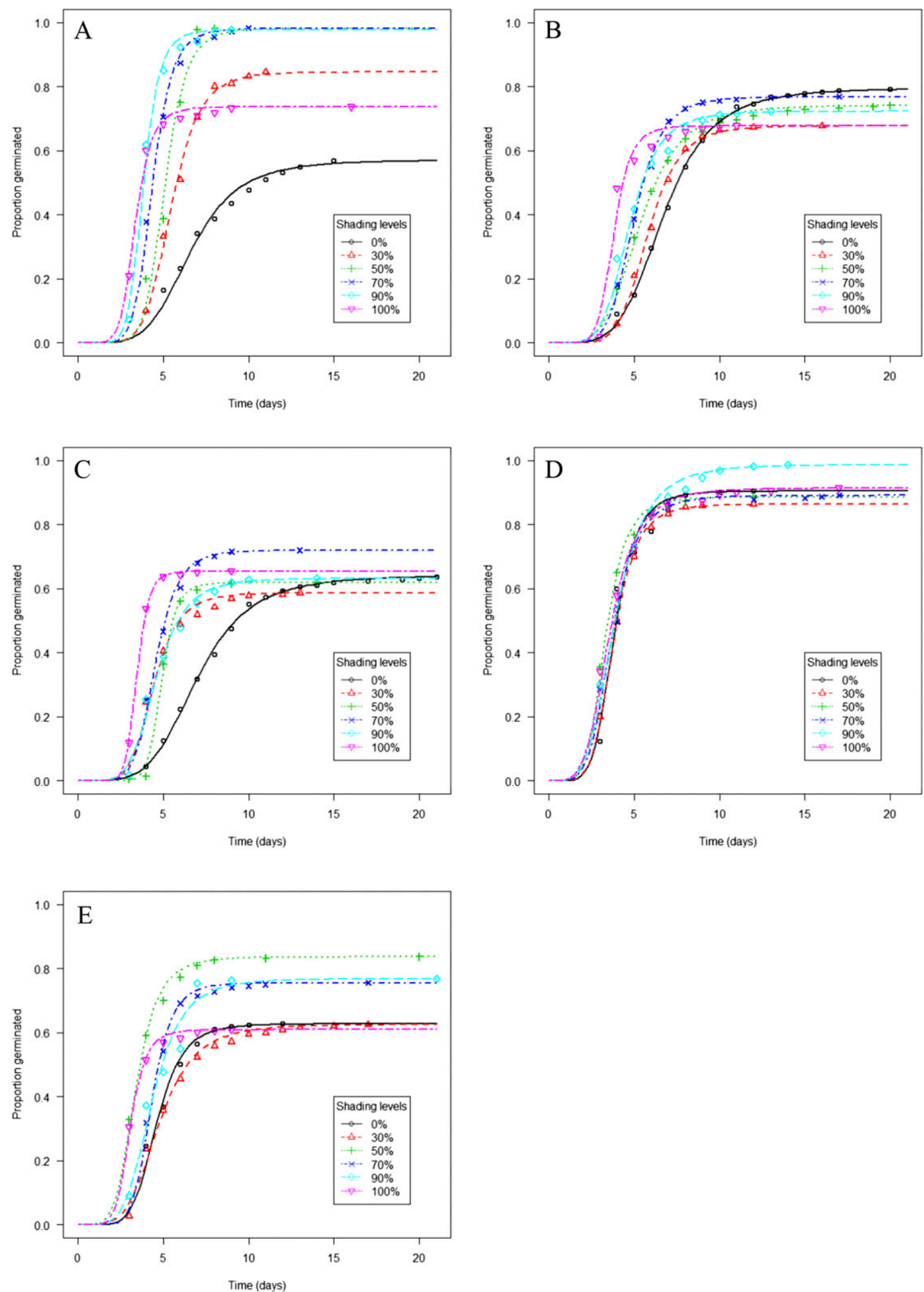

Fig. 2. Fitted germination curves of five cool-season grasses under different shading levels: (A) Diploid perennial ryegrass; (B) meadow fescue; (C) tetraploid perennial ryegrass; (D) annual ryegrass; (E) spreading diploid perennial ryegrass. 
expanded leaf from the top of three random plants per pot (Kim and Beard, 1988).

Vertical growth was determined by measuring the grass height (three random measures by a ruler within each pot) before each mowing and subtracting from this value the mowing height for this study $(2.5 \mathrm{~cm})$. Daily growth rate was calculated by dividing the vertical growth by the days between two mowing events (Cereti et al., 2009). Clippings were collected and oven-dried at $70{ }^{\circ} \mathrm{C}$ for $48 \mathrm{~h}$ before weighing for yield on a dry mass basis (Tan and Qian, 2003).

\section{Statistical analysis}

Expt. 1. Germination data were analyzed as time to event data, because this approach provided a more adequate statistical description of the type of response that resulted from germination experiments (Ritz et al., 2013). Specifically, a two-step procedure that was recently proposed to better characterize germination experiments from complex factorial designs was applied (Jensen et al., 2017). In the first step, relevant parameter estimates (e.g., $\mathrm{T}_{50}$ and final germination) and corresponding standard errors were extracted according to the eventtime approach described by Ritz et al. (2013), by fitting three-parameter log-logistic models to data from each germination curve separately. was:

The model equation used in this study

$$
F(T)=\frac{d}{1+\exp \left[b+\left\{\log (T)-\log \left(T_{50}\right)\right\}\right]},
$$

where $\mathrm{d}$ denotes the proportion of seeds that germinated during the experiment (upper limit or final maximum germination), and $\mathrm{T}_{50}$ is the time (number of days) to reach $50 \%$ of final germination. The parameter $b$ is proportional to the slope of $\mathrm{F}$ at time $\mathrm{T}$ equal to the parameter $T_{50}$. In step 2 , a test of interaction (between species and shade level) was conducted and appropriate pairwise comparisons were carried out using a metaanalytic approach that resulted in a weighted multiway factorial linear mixed model for each of the two model parameters (Jiang and Kopp-Schneider, 2014). The fitted curves were based on selected individual model fits, fairly representative of the overall trends.

Statistical analyses were carried out using the statistical environment $\mathrm{R}$ ( $\mathrm{R}$ Core Team, 2016) with the add-on packages 'drc' (Ritz et al., 2015), 'multcomp' (Hothorn et al., 2008), and 'metafor' (Viechtbauer, 2010) for event-time models, multiple comparisons, and the meta-analytic approach, respectively.

Expt. 2. Data from Expt. 2 were subjected to analysis of variance using R 2.4.0 software to test the main effects of species, environmental condition, and their interaction. Significantly different means were separated at the $0.05 P$ level by the Fisher's protected least significant difference.

\section{Results}

\section{Expt. 1}

Graphical interpretation of the fitted curves showed the model provided a good fit for each genotype and shading level (Fig. 2).
The highest final germination (Table 3) was observed with annual ryegrass at $90 \%$ shade $(98.7 \%)$, and diploid perennial ryegrass at $90 \%, 70 \%$, and $50 \%$ shade $(97.7 \%, 98.4 \%$, and $98.2 \%$, respectively). These germination values were not significantly different among each other, whereas they were significantly higher than all the other combinations (Table 4). In contrast, the lowest germination percentages were recorded for spreading diploid perennial ryegrass at $100 \%, 30 \%$, and $0 \%$ shade $(61.5 \%$, $62.4 \%$, and $63.3 \%$, respectively) and tetraploid perennial ryegrass at $90 \%, 30 \%$, and $50 \%$ shade $(63.4 \%, 58.8 \%$, and $61.5 \%$, respectively). Among the cool-season grasses tested in this study, meadow fescue was the only species in which the nonshaded treatment was in the highest statistical group.

With regard to germination speed, $\mathrm{T}_{50}$ values ranged from $2.9 \mathrm{~d}$ for annual ryegrass at $100 \%$ shade to $6.6 \mathrm{~d}$ for meadow fescue at $0 \%$ shade (Table 3 ). Within each species, shade level and germination speed demonstrated a positive relationship. Within each shading level, there was a species main effect for germination speed such that grasses, ranked from fastest to slowest, were as follows: annual ryegrass, spreading diploid perennial ryegrass, diploid perennial ryegrass, tetraploid perennial ryegrass, and meadow fescue (Table 3 ). The difference between the slowest and fastest germination was higher for tetraploid perennial ryegrass, meadow fescue, and diploid perennial ryegrass $(46.0 \%, 42.4 \%$, and $40.9 \%$, respectively) than for annual ryegrass and spreading ryegrass $(32.7 \%$ and $33.9 \%$, respectively).

Table 3. Final germination percentage and time to reach $50 \%$ germination $\left(\mathrm{T}_{50}\right)$ for each combination of species and shading level (standard errors in parentheses).

\begin{tabular}{lcccc}
\hline \multicolumn{2}{c}{ Treatment combination } & & & \multicolumn{2}{c}{ Germination traits } \\
Species & Shading level (\%) & & Final germination $(\%)$ & $\mathrm{T}_{50}(\mathrm{~d})$ \\
\hline Meadow fescue & 0 & $81.57(1.30)$ & $6.58(0.06)$ \\
& 30 & $67.36(1.58)$ & $5.78(0.06)$ \\
& 50 & $73.83(1.44)$ & $4.96(0.05)$ \\
& 70 & $79.76(1.31)$ & $4.99(0.04)$ \\
Diploid perennial ryegrass & 90 & $75.13(1.41)$ & $4.43(0.05)$ \\
& 100 & $70.03(1.48)$ & $3.79(0.04)$ \\
& 0 & $64.74(1.59)$ & $5.63(0.07)$ \\
& 30 & $76.02(1.36)$ & $4.20(0.04)$ \\
Tetraploid perennial ryegrass & 50 & $98.19(0.39)$ & $4.16(0.03)$ \\
& 70 & $98.37(0.38)$ & $4.17(0.03)$ \\
& 90 & $97.68(0.48)$ & $3.95(0.03)$ \\
Annual ryegrass & 100 & $74.02(1.47)$ & $3.33(0.03)$ \\
& 0 & $63.90(1.61)$ & $6.57(0.08)$ \\
& 30 & $58.83(1.65)$ & $4.67(0.06)$ \\
& 50 & $61.45(1.64)$ & $4.81(0.05)$ \\
Spreading perennial ryegrass & 70 & $72.02(1.51)$ & $4.47(0.04)$ \\
& 90 & $63.37(1.61)$ & $4.36(0.04)$ \\
& 100 & $64.95(1.60)$ & $3.55(0.04)$ \\
& 0 & $87.29(1.08)$ & $4.31(0.05)$ \\
& 30 & $85.96(1.15)$ & $3.79(0.05)$ \\
& 50 & $90.59(0.95)$ & $3.60(0.04)$ \\
& 70 & $87.50(1.11)$ & $3.62(0.04)$ \\
& 90 & $98.65(0.37)$ & $3.47(0.04)$ \\
& 00 & $91.38(0.87)$ & $2.90(0.03)$ \\
& 30 & $63.25(1.61)$ & $4.54(0.06)$ \\
& 50 & $79.39(1.64)$ & $4.52(0.07)$ \\
& 70 & $75.84(1.27)$ & $3.99(0.04)$ \\
& 90 & $61.51(1.64)$ & $3.79(0.04)$ \\
& 100 & & $3.71(0.05)$ \\
& & & $3.00(0.03)$ \\
& & &
\end{tabular}

Expt. 2

Leaf texture. A significant environment $\times$ species interaction was found for leaf texture (Fig. 3). Meadow fescue and diploid perennial ryegrass had significantly wider leaf blades in Environment $2(2.6$ and $1.9 \mathrm{~mm}$, respectively) than in Environment 1 (2.4 and $1.7 \mathrm{~mm}$, respectively), whereas the other species did not show any change with environment. Species had the largest effect on leaf texture, with both meadow fescue and tetraploid perennial ryegrass always having significantly wider leaf blades than diploid perennial ryegrass, whereas spreading diploid perennial ryegrass always had narrower leaf blades (Fig. 3).

Vertical growth rate. A significant environment $\times$ species interaction was found for vertical growth rate (Fig. 3). Predictably, as the environmental conditions became more limiting, vertical growth rate (VGR) was significantly reduced for all species examined in this study. Under optimal conditions and compared with diploid perennial ryegrass $\left(1.24 \mathrm{~cm} \cdot \mathrm{d}^{-1}\right)$, tetraploid perennial ryegrass and annual ryegrass showed significantly higher VGR $\left(1.60 \mathrm{~cm} \cdot \mathrm{d}^{-1}\right.$ and $1.37 \mathrm{~cm} \cdot \mathrm{d}^{-1}$, respectively), meadow fescue performed similarly $\left(1.29 \mathrm{~cm} \cdot \mathrm{d}^{-1}\right)$, whereas spreading diploid perennial ryegrass had significantly lower VGR $\left(1.06 \mathrm{~cm} \cdot \mathrm{d}^{-1}\right)$. Under suboptimal and limiting conditions, growth rate was reduced by more than $50 \%$ compared with the optimum conditions and differences between species became less evident (Fig. 3). Under limiting conditions, annual ryegrass demonstrated a greater VGR than spreading 


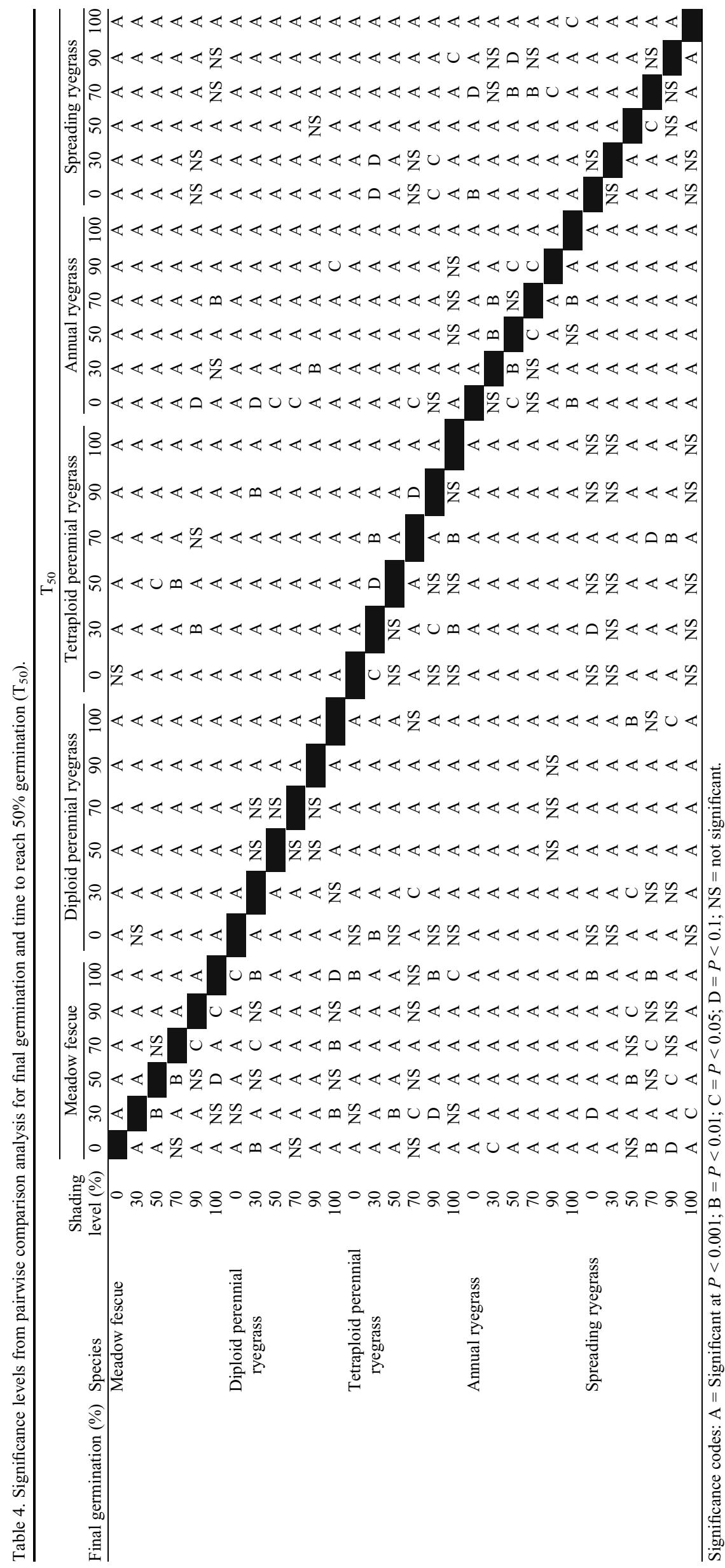

perennial ryegrass, whereas there were no differences between any other mean comparisons.

Clipping yield. Both environment and species had significant effects on clipping yield, whereas the no higher order interaction was present for this variable. As such, results are presented and discussed as main effects only. A significant reduction in clipping yield was observed when the environmental parameters moved from optimal to suboptimal and then to limiting values (Fig. 4). Specifically, DM yield decreased by $48 \%$ moving from Environment 1 to Environment 2 and by 15\% from Environment 2 to Environment 3. Averaged over the environmental conditions (Fig. 4), four of the species performed similarly to each other having yields from 0.68 $\mathrm{mg} \cdot \mathrm{cm}^{-2} \cdot \mathrm{d}^{-1}$ for meadow fescue to 0.74 $\mathrm{mg} \cdot \mathrm{cm}^{-2} \cdot \mathrm{d}^{-1}$ for diploid perennial ryegrass, whereas annual ryegrass demonstrated a significantly higher clipping yield than other species $\left(0.87 \mathrm{mg} \cdot \mathrm{cm}^{-2} \cdot \mathrm{d}^{-1}\right)$.

NDVI. A significant environment $\times$ species interaction was observed for NDVI (Fig. 3). The NDVI values were not different between Environment 1 and Environment 2. In contrast, when the environmental conditions became limiting, NDVI significantly declined for each species, with the exception of tetraploid perennial ryegrass, which showed a relatively constant value across the different environmental conditions. Under suboptimal and limiting conditions, three of the species showed NDVI values not significantly different from diploid perennial ryegrass, whereas annual ryegrass displayed a significantly lower NDVI value than other species.

\section{Discussion}

For all grasses tested in this study, partial shading often had a positive effect on both maximal germination percentage and initial germination speed. However, for those species in which final germination rate was less than $80 \%$ (meadow fescue, tetraploid perennial ryegrass, and diploid spreading ryegrass), overseeding performance would likely be improved by increasing seeding rate. Overall, when considering both final germination percentage and germination speed, the best performance was observed at $90 \%$ shade for diploid perennial ryegrass, annual ryegrass, and spreading diploid perennial ryegrass, whereas at $70 \%$ shade for meadow fescue and tetraploid perennial ryegrass.

These findings suggest that cool-season grasses are better adapted than warm-season grasses to germinate under low light conditions. In a previous study investigating the light requirements for bermudagrass seed germination, Jellicorse et al. (2009) demonstrated that germination of three cultivars was affected by light and the lowest emergence was observed with $60 \%$ and $90 \%$ shade treatments. Similar results were obtained by Zuk et al. (2005) in Kansas on zoysiagrass comparing $40 \%, 65 \%$, and $85 \%$ shade treatments. The authors concluded that successful 
- Diploid perennial ryegrass

Meadow fescue

annual ryegrass

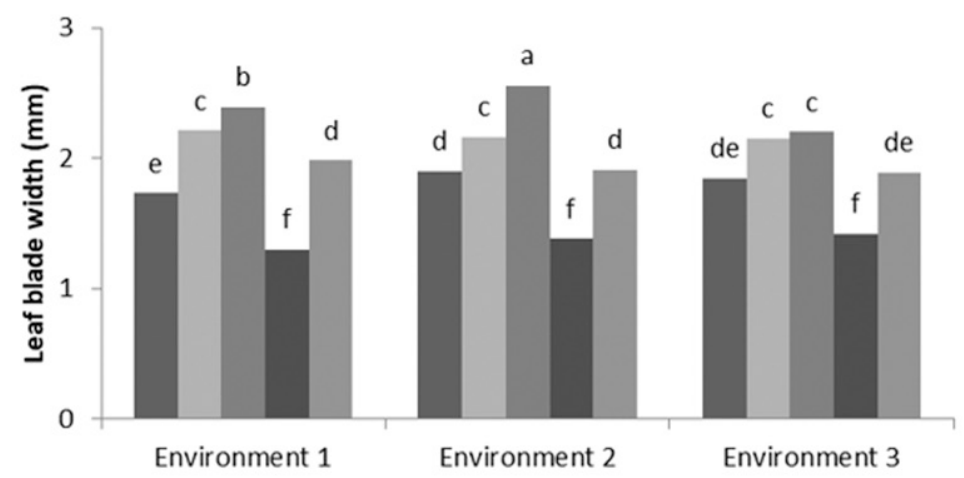

- Diploid perennial ryegrass

Meadow fescue

w Tetraploid perennial ryegrass

annual ryegrass

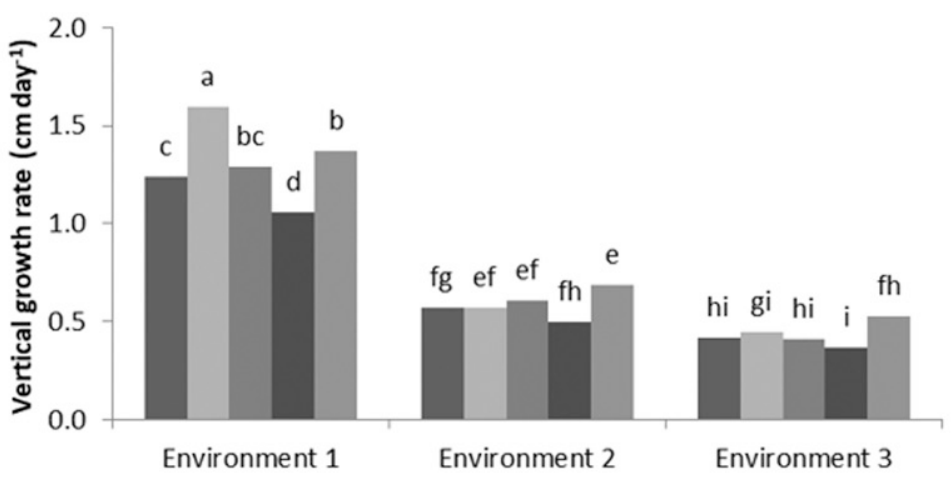

Diploid perennial ryegrass

Meadow fescue

annual ryegrass

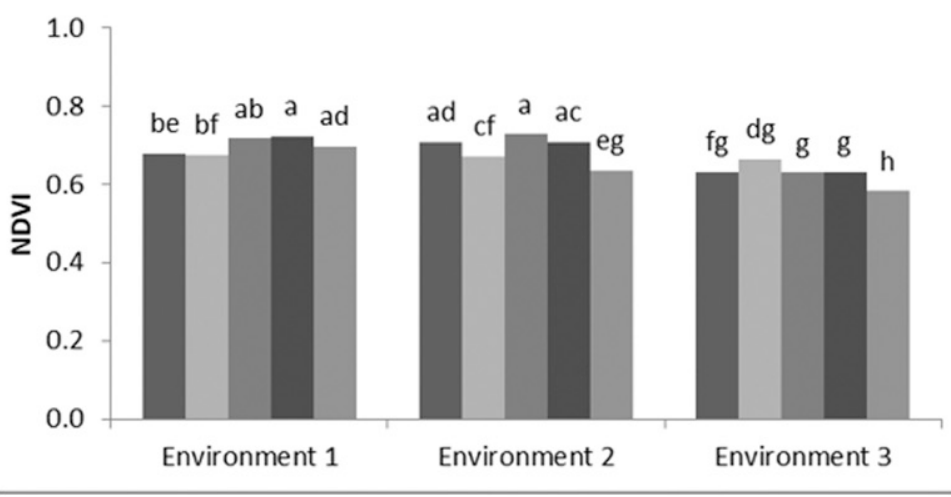

Fig. 3. Leaf texture $(\mathrm{mm})$, vertical growth rate $\left(\mathrm{cm} \cdot \mathrm{d}^{-1}\right)$, and Normalized Difference Vegetation Index (NDVI) of five cool-season grasses under Environment 1 (optimal), Environment 2 (suboptimal), and Environment 3 (limiting). Columns sharing letters are not statistically different according to Fisher's protected least significant difference $(P<0.05)$.

establishment in an overseeded turf may be compromised by the reduction in light at the soil surface.

The first factor determining the success of overseeding is establishment vigor, which depends on the ability of seeds to germinate rapidly. In our study, annual ryegrass was the fastest germinating species, and meadow fescue was the slowest. These results are consistent with previous studies that compared germination characteristics of different cool-season grasses and found annual ryegrass emerging faster than other grasses tested, including perennial ryegrass (Hill et al., 1985; Ward et al., 1974). Our findings also support results by Trappe et al. (2012) from a 3-year study on overseeding establishment of five cool-season species. The authors found that the highest green cover (detected 1 or 2 months after overseeding date) was exhibited by both annual and perennial ryegrass, whereas meadow fescue provided the lowest establishment. In a comparative study on five cool-season grasses, Richardson et al. (2007) showed that both diploid and tetraploid perennial ryegrasses had greater germination vigor than meadow fescue and Poa trivialis L. in Arizona and Arkansas. Our results suggest meadow fescue would not be an ideal species for use in systems requiring rapid germination.

Among the factors that determine turfgrass quality, leaf texture is one of the most important for both aesthetic and technical aspects. In the present study, leaf width was not influenced by photoperiod variation for tetraploid perennial ryegrass, annual ryegrass, and spreading diploid perennial ryegrass, suggesting that this trait is tightly controlled by genetic factors (Hay, 1990). In contrast, meadow fescue and diploid perennial ryegrass showed an unexpected increase of leaf texture moving from a $14 \mathrm{~h}$ (optimal conditions) to $10 \mathrm{~h}$ (suboptimal) photoperiod. A similar result was previously documented for Dactylis glomerata L. grown under a 16- or 24-h photoperiod (Ryle, 1966). However, the performance of meadow fescue and diploid perennial ryegrass in suboptimal conditions seemed to be anomalous compared with that of the other species tested in this study and with the reference literature that generally documents a narrower leaf texture with the decrease of photoperiod (Hay, 1990; Ryle, 1966). It is worth noting that, under the same environmental conditions, both meadow fescue and tetraploid perennial ryegrass always had significantly wider leaf blades, compared with the diploid perennial ryegrass. The fact that tetraploid cultivars had wider leaves than diploid cultivars was previously observed in perennial ryegrass (Sugiyama, 2005). Wider leaf blades have been associated with greater sod tensile strength, suggesting they could have similar effects on wear tolerance (Shearman and Beard, 1975).

Although VGR was found to be well correlated with both turfgrass quality and density, this trait is not always a good indicator of the overall turfgrass performance (Pornaro et al., 2016). This was confirmed by our study, in which spreading diploid perennial ryegrass exhibited both the lowest VGR and the highest clipping yields and NDVI values. These contrasting results were due to the spreading growth habit of cultivar Savant, which is markedly different from the tufted growth habits of the other grasses. Results from the present study, confirmed that longday treatment (LDT) significantly enhanced grass height (Solhaug, 1991). The reason is probably that long-day photoperiods favor 

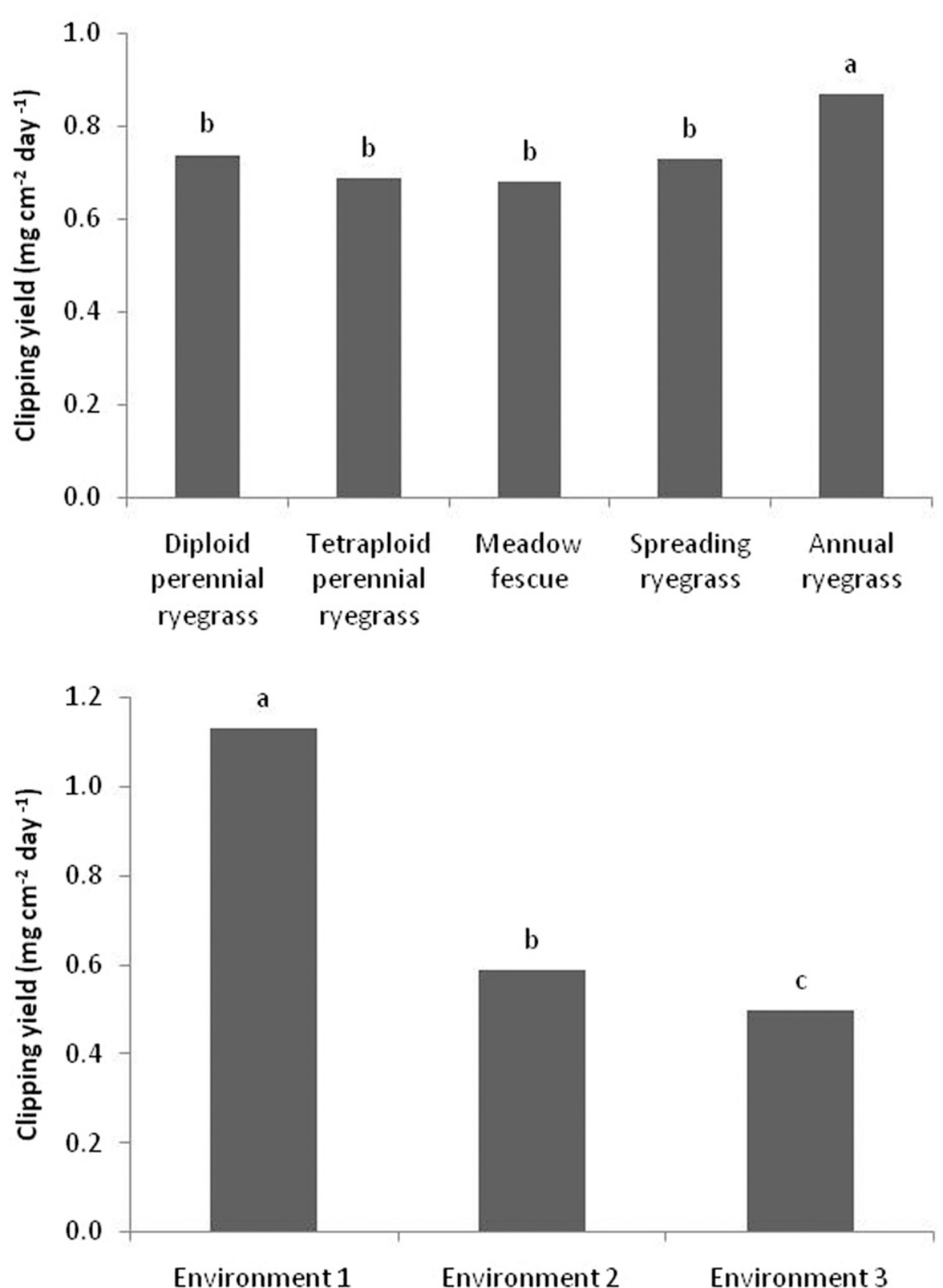

Fig. 4. Clipping yield $\left(\mathrm{mg} \cdot \mathrm{cm}^{-2} \cdot \mathrm{d}^{-1}\right)$ of five cool-season grasses and three environmental conditions (Environment 1, optimal; Environment 2, suboptimal; Environment 3, limiting). Columns sharing letters are not statistically different according to Fisher's protected least significant difference $(P<$ $0.05)$.

gibberellic acid synthesis and this, in turn, promotes shoot and stem elongation (Heide et al., 1985; Junttila et al., 1997; Tan and Qian, 2003).

Clipping yields, together with VGR, were collected to assess the growth characteristics of these alternative grasses relative to control (diploid perennial ryegrass). In our study, all species were equally affected by reduced photoperiod and temperature. Conversely, other authors have observed that the effect of photoperiod variation on DM production varied among species and varieties (Hay and Heide, 1984; Solhaug, 1991). Solhaug (1991) found that stimulation of growth in LDT compared with short-day treatments (SDT) was greater for Bromus inermis Leyss., Dactylis glomerata L., and two cultivars of produced more rapidly under short-day conditions, this accelerated tillering rate is not generally able to compensate for the larger and longer leaves in LDT (Ryle, 1966). Temperature, light intensity, and photoperiod, all presumably contribute to this result, highlighting a complex dynamic in the interaction of these factors (Hay, 1990; Mitchell and Lucanus, 1962; Ryle, 1966; Tan and Qian, 2003). Long-day stimulation of DM production was found to be greatest at low temperatures in many cool-season species (Hay, 1990; Solhaug, 1991). Specifically, in a study aiming to explore the LDT effects on growth of six temperate grasses, Solhaug (1991) showed that, at $9{ }^{\circ} \mathrm{C}$, mean dry weights were more than twice as high in LDT as in SDT, whereas at $18^{\circ} \mathrm{C}$ or higher temperatures, DM production was only slightly higher than SDT. These findings justify the expanding use of supplemental lighting during winter season in many sport facilities around the world. Ultimately, a better understanding of the effects of photoperiod and of other environmental variables on vegetative growth of grasses is needed (Ryle, 1966).

Clipping yields observed in this study for the tested grasses (from 0.7 to $0.9 \mathrm{mg} \cdot \mathrm{cm}^{-2} \cdot \mathrm{d}^{-1}$ ) were slightly higher than observations by Cockerham et al. (2002) for perennial ryegrass $\left(0.6-0.7 \mathrm{mg} \cdot \mathrm{cm}^{-2} \cdot \mathrm{d}^{-1}\right)$ and by Tan and Qian (2003) for Kentucky bluegrass (0.5 $\left.\mathrm{mg} \cdot \mathrm{cm}^{-2} \cdot \mathrm{d}^{-1}\right)$. The clipping yields were very similar to observations by Richardson et al. (2007) for different cool-season species (from 0.6 to $1.0 \mathrm{mg} \cdot \mathrm{cm}^{-2} \cdot \mathrm{d}^{-1}$ ) during spring in an open-field trial in Alabama. Furthermore, our findings on the clipping yield and VGR of annual ryegrass confirmed that this species has accelerated growth characteristics compared with perennial ryegrass (Richardson, 2004). This feature may cause problems in the management of overseeding mixtures with perennial ryegrass and may increase the mowing cost of turf.

One of the major reasons for overseeding an established warm-season sport turf is to provide color during the winter season and turfgrass managers and spectators generally prefer a deeper green color for sport turf facilities. Thus, the ability to retain color under suboptimal or limiting environmental conditions represents a crucial aspect for cultivar selection. NDVI was found to be closely related to visual evaluation of turf color (Bell et al., 2002) and so it can be used as a good indicator for this turfgrass quality trait. In our study, all species had similar NDVI value to diploid perennial ryegrass in suboptimal and limiting environment, with the exception of annual ryegrass that showed lighter green color in these conditions. These results confirm earlier studies that showed annual ryegrass had lower quality and color ratings than perennial ryegrass during the winter season (Richardson, 2004; Schmidt and Shoulders, 1980). The reduced color of annual ryegrass, along with its accelerated growth, may limit its use in overseeding mixtures for sport turfs. Moreover, our findings 
are consistent with those by Richardson et al. (2007), which showed tetraploid perennial ryegrass had similar or even deeper green color than diploid perennial ryegrass during the winter season in three different locations of the United States. In contrast, although the same authors showed a lighter green color for meadow fescue compared with perennial ryegrass, both in winter and spring seasons, we did not find any significant differences in NDVI value between meadow fescue and diploid perennial ryegrass.

\section{Conclusions}

These studies explored germination features and performance of four cool-season grasses under restricted light, photoperiod, and temperature, and add needed information on the potential use of these species for overseeding dormant turf in modern sport buildings. In summary, each species displayed the following characteristics when compared with the industry standard, diploid perennial ryegrass: meadow fescue had lower germination percentage and speed, coarser leaf texture, similar growth characteristics and NDVI value; tetraploid perennial ryegrass had lower germination percentage and speed, coarser leaf texture, similar growth characteristics in suboptimal and limiting environment, and similar NDVI value; annual ryegrass had similar germination percentage but faster initial germination, similar leaf texture in suboptimal and limiting condition, accelerated growth characteristics, lower NDVI value in suboptimal and limiting conditions; spreading ryegrass had lower germination percentage but higher germination speed, finer leaf texture, lower vertical growth but similar clipping yield, and similar NDVI value in suboptimal and limiting condition. Future studies should focus on the specific light requirement for these grasses, to optimize their management in stadiums where winter, supplemental lighting is currently used.

\section{Literature Cited}

Adams, S.R. and F.A. Langton. 2005. Photoperiod and plant growth: A review. J. Hort. Sci. Biotechnol. 80(1):2-10.

Bell, G.E., D.L. Martin, S.G. Wiese, D.D. Dobson, M.W. Smith, M.L. Stone, and J.B. Solie. 2002. Vehicle-mounted optical sensing: An objective means for evaluating turf quality. Crop Sci. 42(1):197-201.

Cereti, C.F., F. Rossini, B. Barbetti, and S. Sbrilli. 2004. Effects of shading on Lolium perenne and Poa pratensis turf. Acta Hort. 661:227-231.

Cereti, C.F., F. Rossini, and R. Ruggeri. 2009. Reduction of irrigation on tall fescue and bermudagrass turfs in a Mediterranean environment. Intl. Turfgrass Soc. Res. J. 11:9-18.

Cereti, C.F., R. Ruggeri, and F. Rossini. 2010. Cool-season turfgrass species and cultivars: Response to simulated traffic in central Italy. Ital. J. Agron. 5(1):53-59.

Cockerham, S.T., S.B. Ries, G.H. Riechers, and V.A. Gibeault. 2002. Turfgrass growth response under restricted light: Growth chamber studies. In: California turfgrass culture. University of
California Cooperative Extension 52(3-4):1315.

Du, H., Z. Wang, and B. Huang. 2009. Differential responses of warm-season and cool-season turfgrass species to heat stress associated with antioxidant enzyme activity. J. Amer. Soc. Hort. Sci. 134(4):417-422.

Fontanier, C. and K. Steinke. 2017. Performance of annual and perennial ryegrass mixtures for winter overseeding into three warm-season turfgrass species. Intl. Turfgrass Soc. Res. J. 13:305-311

Gardner, D. and J. Taylor. 2002. Change over time in quality and cover of various turfgrass species and cultivars maintained in shade. HortTechnology 12:465-469.

Hammer, P.A. and D.A. Hopper. 1997. Experimental design, p. 177-187. In: R.W. Langhans and T.W. Tibbitts (eds.). Plant growth chamber handbook. Iowa State Univ., Ames, IA.

Hargey, D., B. Wherley, C. Reynolds, R. White, and G. Parker. 2016. Performance of winter overseeded and colorant-treated 'tifway' bermudagrass receiving weekly irrigation and simulated traffic. HortScience 51:580-587.

Harris, W., K.K. Pandey, Y.S. Gray, and P.K. Couchman. 1979. Observations on the spread of perennial ryegrass by stolons in a lawn. N.Z. J. Agr. Res. 22(1):61-68.

Hay, R.K.M. 1990. Tansley Review No. 26: The influence of photoperiod on the dry matter production of grasses and cereals. New Phytol. 116:233-254.

Hay, R.K.M. and O.M. Heide. 1984. The response of high-latitude Norwegian grass cultivars to long photoperiods and cool temperatures. Proceedings of the 10th General Meeting of the European Grassland Federation. p. 46-50. Ås, Norway.

Hayes, P. 1971. Stoloniferous perennial ryegrass (Lolium perenne) in Northern Ireland paddocks. Record of Agr. Res., Ministry Agr. Northern Ireland. 19:63-64.

Heide, O.M., M.G. Bush, and L.T. Evans. 1985. Interaction of photoperiod and gibberellin on growth and photosynthesis of high-latitude $\mathrm{Poa}$ pratensis. Physiol. Plant. 65:135-145.

Hill, M.J., C.J. Pearson, and A.C. Kirby. 1985. Germination and seedling growth of prairie grass, tall fescue and Italian ryegrass at different temperatures. Austral. J. Agr. Res. 36(1): $13-24$.

Horgan, B.P. and F.H. Yelverton. 2001. Removal of perennial ryegrass from overseeded bermudagrass using cultural methods. Crop Sci. 41(1): $118-126$

Hothorn, T., F. Bretz, and P. Westfall. 2008. Simultaneous inference in general parametric models. Biometrical J. 50:346-363.

Jellicorse, W., M. Richardson, A. Patton, and J. McCalla. 2009. Light requirement for emergence of turf-type bermudagrass seed. Arkansas Agr. Expt. Sta. Res. Serv. 568(January):17-21.

Jensen, S.M., C. Andreasen, J.C. Streibig, E. Keshtkar, and C. Ritz. 2017. A note on the analysis of germination data from complex experimental designs. Seed Sci. Res. 27(4): 321-327.

Jiang, X. and A. Kopp-Schneider. 2014. Summarizing EC50 estimates from multiple dose-response experiments: A comparison of a meta-analysis strategy to a mixed-effects model approach. Biometrical J. 56(3):493-512.

Junttila, O., O. Heide, B. Lindgard, and A. Ernstsen. 1997. Gibberellins and the photoperiodic control of leaf growth in Poa pratensis. Physiol. Plant. 101:599-605.
Kim, K. and J. Beard. 1988. Comparative turfgrass evapotranspiration rates and associated plant morphological characteristics. Crop Sci. 28(2): 328-331.

Kydd, D. 1966. The effect of intensive sheep stocking over a five-year period on the development and production of the sward. J. Brit. Grassland Soc. 21:284-288.

Masin, R. and S. Macolino. 2016. Seedling emergence and establishment of annual bluegrass (Роа аппиа) in turfgrasses of traditional and creeping perennial ryegrass cultivars. Weed Technol. 30:238-245.

Mazur, A.R. and J.S. Rice. 1999. Impact of overseeding bermudagrass with various amounts of perennial ryegrass for winter putting turf. HortScience 34:864-866.

Milberg, P., L. Andersson, and K. Thompson. 2000. Large-seeded species are less dependent on light for germination than small-seeded ones. Seed Sci. Res. 10(1):99-104.

Mitchell, K.J. 1956. The influence of light and temperature on the growth of pasture species. Proceedings of the Seventh International Grassland Congress. p. 58-69. Palmerston North, New Zealand.

Mitchell, K.J. and R. Lucanus. 1962. Growth of pasture species under controlled environment. N.Z. J. Agr. Res. 5:135-144.

Nelson, L.R., J. Crowder, and H.B. Pemberton. 2005. Performance and transition date of a turf type annual ryegrass in comparison to perennial ryegrass and fine fescues. HortTechnology 15:304-308.

Di Paola, J.M. and J.B. Beard. 1992. Physiological effects of temperature stress, p. 231-262. In: D.V. Waddington, R.N. Carrow, and R.C. Shearman (eds.). Turfgrass. Agron. Monogr. 32. American Society of Agronomy, Madison, WI.

Pons, T.L. 2000. Seed responses to light, p. 237 260. In: M. Fenner (ed.). Seeds: The ecology of regeneration in plant communities. $\mathrm{CAB}$ International, Wallingford, UK.

Pornaro, C., E. Barolo, F. Rimi, S. Macolino, and M. Richardson. 2016. Performance of various cool-season turfgrasses as influenced by simulated traffic in northeastern Italy. Eur. J. Hort. Sci. 81(1):27-36.

R Core Team. 2016. R: A language and environment for statistical computing.

Richardson, M.D. 2004. Morphology, turf quality, and heat tolerance of intermediate ryegrass. HortScience 39:170-173.

Richardson, M.D., K.W. Hignight, R.H. Walker, C.A. Rodgers, D. Rush, J.H. McCalla, and D.E. Karcher. 2007. Meadow fescue and tetraploid perennial ryegrass - Two new species for overseeding dormant bermudagrass turf. Crop Sci. 47(1):83-90.

Ritz, C., F. Baty, J.C. Streibig, and D. Gerhard. 2015. Dose-response analysis using R. PLoS One 10(12):1-13.

Ritz, C., C.B. Pipper, and J.C. Streibig. 2013. Analysis of germination data from agricultural experiments. Eur. J. Agron. 45:1-6.

Ruggeri, R., M.E. Provenzano, and F. Rossini. 2016. Effect of mulch on initial coverage of four groundcover species for low input landscaping in a Mediterranean climate. Urban For. Urban Green. 19:176-183.

Ryle, G.J. 1966. Effects of photoperiod in the glasshouse on the growth of leaves and tillers in three perennial grasses. Ann. Appl. Biol. 57:257-268.

Scarici, E., R. Ruggeri, M.E. Provenzano, and F. Rossini. 2018. Germination and performance of seven native wildflowers in the Mediterranean landscape plantings. Ital. J. Agron. 13(2): 163-171. 
Schmidt, R.E. and J.F. Shoulders. 1980. Seasonal performance of selected temperate turfgrasses overseeded on bermudagrass turf for winter sports. Proceedings of the Third International Turfgrass Research Conference. p. 75-86. Madison, WI.

Shearman, R.C. and J.B. Beard. 1975. Turfgrass wear tolerance mechanisms: III. physiological, morphological, and anatomical characteristics associated with turfgrass wear tolerance. Agron. J. 67(2):215-218.

Shin, J.S., P. Raymer, and W. Kim. 2006. Environmental factors influencing germination in seeded seashore paspalum. HortScience 41:1330-1331.

Solhaug, K.A. 1991. Influence of photoperiod and temperature on dry matter production and chlorophyll content in temperate grasses. Norwegian J. Agr. Sci. 5:365-383.
Sugiyama, S.I. 2005. Polyploidy and cellular mechanisms changing leaf size: Comparison of diploid and autotetraploid populations in two species of Lolium. Ann. Bot. 96(5):931-938.

Summerford, J.A., D.E. Karcher, and M.D. Richardson 2016. Traffic tolerance of overseeded meadow fescue and tetraploid ryegrass as affected by cultural practices. Acta Hort. 1122:97-102.

Summerford, J.A., D.E. Karcher, M.D. Richardson, J. Patton, and J.W. Boyd. 2009. Cultural practice effects on the spring transition of overseeded meadow fescue and tetraploid perennial ryegrass sports fields. Intl. Turfgrass Soc. Res. J. 11:501-510.

Tan, Z.G. and Y.L. Qian. 2003. Light intensity affects gibberellic acid content in Kentucky bluegrass. HortScience 38:113-116.

Trappe, J.M., M.D. Richardson, and A.J. Patton. 2012. Species selection, pre-plant cultivation, and traffic affect overseeding establishment in bermudagrass turf. Agron. J. 104(4):11301135.

Viechtbauer, W. 2010. Conducting meta-analyses in $\mathrm{R}$ with the metafor package. J. Stat. Softw. 36(3): $1-48$

Ward, C.Y., E.L. Mc Whirter, and W.R. Thompson. 1974. Evaluation of cool-season turf species and planting techniques for overseeding bermudagrass golf greens. Proceedings of the Second International Turfgrass Research Conference. p. 480-495. Madison, WI.

Zuk, A.J., D.J. Bremer, and J.D. Fry. 2005. Establishment of seeded zoysiagrass in a perennial ryegrass sward: Effects of soil-surface irradiance and temperature. Intl. Turfgrass Soc. Res. J. 10:302-309. 